\title{
Ön çapraz bağ yaralanmalarının tedavisinde güncel literatür bilgileri
}

\section{Current literature in the treatment of anterior cruciate ligament injuries}

\author{
Vahdet Uçan, Anıl Pulatkan, Nurzat Elmalı \\ Bezmialem Vakıf Üniversitesi, Tıp Fakültesi, Ortopedi ve Travmatoloji Anabilim Dalı, İstanbul
}

Ön çapraz bağ (ÖçB) yaralanması spor cerrahisi ile ilgilenen ortopedi ve travmatoloji uzmanlarının en sık karşılaştıkları durumlardan birisidir. Teknolojinin hızla ilerlemesi, temel bilimlerdeki araştırmaların genişlemesi, cerrahi sırasında ÖÇB'nin korunmasına olan isteğin artması, biyolojik ajanların popülarize olması, ÖÇB yaralanmasını önlemeye yönelik ilginin artması gibi durumlar güncel literatürü şekillendirmektedir. Literatürdeki tüm bu çalışmaların amacı hastaları yaralanma öncesi durumlarına güvenli bir şekilde döndürebilmektir. Bu derlemede; güncel literatür taraması yapılarak ÖÇB yaralanmasının tedavisindeki yenilikler ve tartışmalı konular gözden geçirilmiştir.

Anahtar sözcükler: ön çapraz bağ yaralanması; tedavi; güncel literatür; diz

\begin{abstract}
Anterior cruciate ligament (ACL) injury is one of the most frequently encountered cases of ortho-pedists interested in sports surgery. Conditions such as the rapid advancement of technology, the expansion of research in basic sciences, the increase in the desire to preserve ACL during surgery, the popularity of biological agents, and the increased interest in preventing ACL injury are shaping the current literature. The purpose of all these studies in the literature is to return patients safely to their pre-injury status. In this review; by reviewing the current literature, innovations and controversial issues in the treatment of ACL injury were reviewed.
\end{abstract}

Key words: anterior cruciate ligament injury; treatment; current literature; knee

\section{O̊} n çapraz bağ (ÖÇB) tibianın öne translasyonunu sınırlayan ve hem frontal hem de transvers planda dizin rotasyonel stabilitesini sağlayan yapıdır. ${ }^{[1]}$ ÖÇB yaralanması pivot tipi sportif aktivitelerdeki diz yaralanmalarının \%64'ünü oluşturmaktadır ve yalnızca Amerika Birleşik Devletleri(ABD)'nde yılda yaklaşık 1,7 milyar dolar maliyetle 200.000 ön çapraz bağ rekonstrüksiyonu (ÖÇBR) yapılmaktadır. ${ }^{[2,3]}$ ÖÇB, insan vücudunda en çok çalışılan anatomik yapılar arasındadır ve elde edilen çok sayıda biyomekanik, biyolojik ve klinik veri nedeniyle ilgili literatür sürekli güncellenmektedir. Bu yazıda alt başlıklar şeklinde ÖÇB yaralanması tedavisindeki güncel konular ele alınmıştır.

\section{KONSERVATIF/CERRAHI TEDAVI}

ÖÇB total yırtığında gerek erişkinlerde gerekse pediatrik grupta konservatif tedavi, tekrarlayan instabilite, sekonder kıkırdak ve menisküs yaralanmalarına bağıı hastaların çoğunda yaralanma öncesi aktivite seviyesine geri dönememe nedeniyle önerilmemektedir. ${ }^{[4,5]}$ Fakat uzun dönem sonuçları açısından konservatif tedavi ile cerrahi tedavi sonuçları hala tartışmalıdır. 2016 yılında yapılan Cochrane derlemesinde, yetişkin ÖÇB yaralanmasında fizik tedaviyle konservatif takip edilen hastalar ile rekonstrüksiyon yapılan hastaların karşılaştırıldığı randomize kontrollü çalışmalar değerlendirilmiştir. ${ }^{[6]}$ Sadece bir çalışmada, hastalar tarafından bildirilen subjektif diz skorlarında cerrahi ve konservatif tedavi arasında fark bulunmamıştır. Bu çalışmada akut ÖÇB yaralanması olan 59 hastaya yapılandırılmış bir rehabilitasyon programı uygulanırken 62 hastaya ise erken ÖÇBR yapılmış, iki ve beşinci yılın sonunda hastalar tarafından bildirilen subjektif diz skorunda her iki grupta benzer sonuçlar bildirilmiştir. Ancak bu çalışmada cerrahi yapılan grupta üç greftte yetersizlik varken, konservatif tedavi grubuna randomize edilen katılımcıların \%39'una (59 hastanın 23 üne) ÖÇB kopmasından sonraki iki yıl içinde, \%51'ine

- İletişim adresi: Prof. Dr. Nurzat Elmalı, Bezmialem Vakıf Üniversitesi Hastanesi, Ortopedi ve Travmatoloji Kliniği, Adnan Menderes Bulvarı, Vatan Cad., 34093 Fatih, İstanbul Tel: 0532 - 4359129 e-posta: nelmali@gmail.com

- Geliș tarihi: 19 Nisan $2020 \quad$ Kabul tarihi: 4 Mayıs 2020 
(59 hastanın 30 una) ise beş yıl içinde devam eden diz instabilitesi nedeniyle ÖÇBR yapılmıştır. ${ }^{[7]} \mathrm{Bu}$ çalışma sorunlu tasarım ve veri yorumlaması nedeniyle yüksek bias (ön yargı) içermektedir ve kanıt kalitesi düşük olarak değerlendirilmiştir. ${ }^{[6]}$ Gföller ve ark.'nın yapmış oldukları çalışmada, 20 yıldan uzun süre konservatif takip edilen 21 hastanın subjektif sonuçlarının iyi olduğu bildirilmiştir. Fakat bu hastaların hepsinde radyolojik olarak belirgin osteoartrit gelişmiştir. ${ }^{\left[{ }^{[8]}\right.}$

Başka bir retrospektif çalışmada ise ÖÇB yırtığı sonrası konservatif veya cerrahi tedavi edilen 50 üst seviye sporcunun 20 yıllık sonuçları incelenmiştir. Cerrahi ve konservatif tedavi arasında diz osteoartriti açısından fark bulunamamıştır. Ameliyat grubunda diz stabilitesi daha iyi olmasına rağmen, uzun dönemde daha iyi subjektif ve objektif fonksiyonel sonuçlar elde edilememiştir. ${ }^{[9]}$ Sonuç olarak özellikle instabiliteyi önleme açısından ve erken-orta dönem iyi sonuçlar göz önüne alındığında cerrahi tedavinin konservatif tedaviye üstün olduğu kabul edilir.

\section{KISMI ÖN ÇAPRAZ BAĞ YIRTIKLARI}

Kısmi yırtıkları konservatif mi takip edelim? Yırtık olan demeti tamir mi edelim? Sağlam ÖÇB kalıntısının korunması ile tek demet ÖÇBR mi yapalım? Tüm ÖÇB'yi debride edip standart ÖÇBR mi yapalım? Maalesef bu soruların literatürde net bir cevabı yoktur.

Kısmi ÖÇB yırtıkları yaklaşık 50 yıl önce tanımlanmıştır, ancak bu yaralanmalar için en uygun tedavi halen tartışılmaktadır. İzole ÖÇB yırtıklarının yaklaşık \%10 ile \%28'i kısmi ön çapraz bağ yırtığı şeklindedir. ${ }^{[10]}$ Kısmi yırtıkların önemli bir kısmı (\%30-35) zaman içinde tam yırtığa dönüşmektedir. Hareketli temas sporlarına katıIım ile 20 yaş ve altı, tam bir yırtığa dönüşüm için önemli risk faktörleri olarak belirlenmiştir. ${ }^{[11,12]}$ Tam bir ÖÇB yırtığının ise spontan iyileşme ve yeniden modelleme kapasitesi kötüdür. ${ }^{[13]}$ Barrack ve ark.'nın kısmi ve tam ÖÇB yırtıklarında konservatif tedavi sonuçlarını karşılaştırdıkları çalışmada; kısmi yırtıklarda daha iyi klinik skorlar ve daha az ÖÇBR gereksinimi bulmuşlardır. ${ }^{[14]}$ Giderek artan bilimsel kanıtlar kalan sağlam ÖÇB liflerinin korunmasının ve ilave tek demet rekonstrüküsyonu ile güçlendirmenin damarlanma, propriyosepsiyon ve kinematik açıdan faydalı olduğunu göstermiştir. ${ }^{[11-14]}$ Ancak yayınlanmış çalışmaların çoğu sadece küçük bir hasta grubunu içermektedir ve seçici rekonstrüksiyon ile standart rekonstrüksiyonu karşılaştırmak için kontrol grubu olmayan çalışmalardır. Bununla birlikte, kısmi rekonstrüksiyonun klinik sonuçları umut vericidir ve komplikasyon oranı çok düşüktür. ${ }^{[15]}$ Literatürde kısmi yırtıkta tamir ile ilgili başarılı sonuçlar gösterilmiştir. ${ }^{[16]}$
Propriosepsiyon, greftin iyileşmesi veya yeniden şekillenmesi ile ilgili sonuçları objektif olarak değerlendirmek ve bu yöntemlerin standart tekniklere göre avantajını göstermek için prospektif, randomize, çift kör çalışmalara ihtiyaç vardır.

\section{TÜNEL POZISYONU: NONANATOMIK/ANATOMIK?}

Uygun olmayan tünel pozisyonu, ön çapraz bağ rekonstrüksiyonu başarısızlığının en yaygın nedenlerinden biridir. Tünel yerleşimindeki küçük değişiklikler, sonuçta önemli farklılıklara neden olabilir. Geleneksel anatomik olmayan rekonstrüksiyonlarda gözlenen vertikal yönlendirilmiş greftler, sagittal düzlemde (anterior-posterior) stabiliteyi sağlasa da rotasyonel stabiliteyi sağlayamamaktadır. ${ }^{[17]}$

Tünellerin anatomik yerleşimi diz stabilitesinin artmasına ve doğal diz kinematiğinin daha doğru bir şekilde yeniden oluşturulmasına yardımcı olur. Güncel eğilim, doğal fonksiyonel kinematiği yeniden oluşturmak için hem tibial hem de femoral doğal ÖÇB ayak izlerinin kullanıldığı anatomik rekonstrüksiyon yönündedir. ${ }^{[18]}$

Anteromedial portal tekniği anatomik femoral tünel yerleşimi sağlar ancak diz hiperfleksiyonu ve asistan gereklidir. Yapılan son meta-analizde; anteromedial portal tekniğin, ameliyat sonrası stabilite ve dizde fonksiyonel iyileşme açısından transtibial teknikten daha üstün olduğunu göstermiştir. ${ }^{[19]}$ Daha vertikal ve yüksek femoral tünele neden olan transtibial tekniğin kullanımı günümüzde önemli ölçüde azalırken anteromedial portalden klavuz aracılığıyla yapılan anatomik teknik ön plana geçmiştir. ${ }^{[20]}$

\section{TEK VEYA ÇIFT DEMET?}

Tek ile çift demet rekonstrüksiyonu karşılaştıran çalışmalarda hem anteromedial hem de posterolateral demetin rekonstrükte edildiği çift demet rekonstrüksiyonun biyomekanik olarak doğal ön çapraz bağa daha yakın olduğu gösterilmiştir. ${ }^{[21,22]}$ Bununla beraber 2012 Cochrane derlemesinde çift demet tekniğin bazı objektif ölçümlerde (KT-1000 skoru, yaralanma öncesi aktivite seviyesi vb.) tek demete göre üstün olduğu görülmüş olsa da diğer ölçümlerde (subjektif diz skoru, uzun dönem diz ağrısı, komplikasyonlar) tek demete göre göreceli üstünlüğü kanıtlanamamıştır. ${ }^{[23]}$

Yine beş randomize kontrollü çalışmanın dahil edildiği bir derlemede; en az beş yıl takip edilen 294 hasta (150 çift demet, 144 tek demet) incelenmiş ve çift demet tekniğinin; diz stabilitesi, klinik fonksiyon, greft başarısızlık oranı, osteoartrit değişiklikleri ile ilgili sonuçlarda tek demet tekniğinden üstün olmadığı gösterilmiştir. ${ }^{[24]}$ 
Özetle tek demet tekniğine göre üstünlüğü olmayan, revizyon cerrahisi son derece problemli olan çift demet tekniği, şu an için popülaritesini yitirmiş durumdadır.

\section{TESPIT TIPLERi}

Hem femoral hem tibial bir çok tespit materyali seçeneği mevcuttur ancak bu materyallerin birbirlerine üstünlüğü hakkında net bir fikir birliği yoktur. Tibor ve ark., greft fiksasyonu için birinci nesil biyolojik olarak emilebilen vidaların kullanımında bir azalmaya karşılık biyokompozit fiksasyona doğru bir eğilim bildirmişlerdir. ${ }^{[20]}$

Femoral kortikal tespitte kullanılan sabit (fixed-loop devices) veya ayarlanabilir (adjustable-loop devices) materyalleri karşılaştıran çalışmalarda her ne kadar sabit materyaller biyomekanik olarak üstün olsalar da klinik skorlar ve greft rerüptürü (tekrarlayan yırtığı) oranları iki grup arasında benzer bulunmuştur. ${ }^{[25,26]}$

\section{GREFT SEÇENEKLERi}

En sık kullanılan otogreftler; kemik patellar tendon kemik (BPTB), hamstring tendonu (HT) ve kuadriseps tendonudur (QT). ÖÇBR'de greft seçimi oldukça araştırılmış olmasına rağmen halen tartışılan bir konudur. ${ }^{[27]}$ Çalışmaların çoğunda farklı otogreft seçenekleri arasında başarısızılı oranı ve klinik skorlar açısından büyük bir fark olmadığını bildirmektedir. ${ }^{[28]}$ Hangi greft tipinin seçileceğine genellikle hastaya özgü faktörlere (yaş, iskelet gelişimi, revizyon cerrahisi gibi) göre karar verilir. HT, BPTB ile karşılaştırıldığında biraz daha yüksek bir rüptür oranına sahip olabilir (2,84'e karşı 2,80). Bununla birlikte, BPTB grefti ile yapılmış ÖÇBR'de kısa ve orta dönem takiplerde daha yüksek diz önü ağrısı bildirilmiştir. Uzun süreli izlemde durumun böyle olmadığı gösterilmiştir. Allogreftler 35 yaşın üzerindeki hastalarda ve revizyon ÖÇBR için uygun bir seçenektir; bununla birlikte, genç hastalarda re-rüptür oranı allogreftler ile önemli ölçüde artmaktadır.

Özellikle QT ile sanılanın aksine morbiditeyi etkilemeden HT'ye eşit veya daha iyi fonksiyonel sonuçların elde edildiği çalışmalar mevcuttur. ${ }^{[29]}$

Otogreft ile ışınlanmış ve ışınlanmamış allogreftleri karşılaştıran bir meta-analizde; otogreftin fonksiyonel sonuçlar ve yan etkiler açısından ışınlanmış allogrefte göre üstünlüğü saptanmıştır. Fakat otogreft ile ışınlanmamış allogreftler arasında üstünlük saptanmamıştır. ${ }^{[30]}$

Son yıllarda üzerinde durulan bir diğer konu ise HT greftinin ince olduğu durumlarda $(<8 \mathrm{~mm}), \mathrm{HT}$ otogreftine allogreft eklenerek hibrid bir greft oluşturulmasının sonuçları olumlu yönde etkileyip etkilemediğidir.
$\mathrm{Bu}$ konuda yapılan çalışmalarda net bir fikir birliği olmamakla beraber genel olarak iki grup arasında sonuçların farklı olmadığı gösterilmiştir. ${ }^{[31,32]}$

Cerrah her greft tipinin biyomekanik özelliklerine hâkim olmalı, gerektiği zaman kendi rutininin dışına çıkıp farklı greftler alabilecek donanımda olmalıdır.

\section{ÖN ÇAPRAZ BAĞ YIRTIKLARINDA PRIMER TAMIR}

Son zamanlarda, doğal ÖÇB anatomisine, biyomekaniğine ve nöro-duyusal işlevine daha çok yaklaşabilmek adına ÖÇB tamirine artan bir ilgi vardır. İlginin bu yöne kaymasındaki nedenler; MRG kalitesinin artması, rejeneratif tıp ve doku mühendisliğindeki gelişmeler, artroskopik teknik ve enstrümantasyondaki ilerlemeler ve rehabilitasyonda erken mobilizasyonun öneminin daha iyi anlaşılması şeklinde sıralanabilir. ${ }^{[33,34]}$ ÖÇB tamiri için dört çeşit teknik tanımlanmıştır. Bunlar, dinamik intra-ligamenter stabilizasyon (DIS) (Ligamys ${ }^{\circledR}$ ), köprü destekli onarım (BEAR), internal brace kullanımı ve suture anchor ile yeniden tespittir. ${ }^{[35]}$

Genel olarak, primer ÖÇB tamiri; travmadan sonraki bir ayı geçmemiş, iyi doku kalitesine sahip proksimal yırtıklarda düşünülmelidir. ${ }^{[36,37]}$ Son yıllarda yapılan derlemelerde primer tamir ile ilgili bildirilen başarısızIık ve yeniden ameliyat oranları oldukça tutarsızdır. Bu nedenle halen ÖÇBR ile primer ÖÇB tamiri kıyaslandığında ÖÇBR, ÖÇB primer tamirine göre daha çok tercih edilmektedir. ${ }^{[38-40]}$

\section{ANTEROLATERAL LIGAMAN}

Claes ve ark.'nın 2013 yılında anterolateral ligamanı (ALL) tanımlamasından sonra dizde eklem dışı anterolateral yumuşak doku yapılara olan dikkat artmıştır. ${ }^{[41]}$ Biyomekanik, klinik ve kadavra çalışmalarının çoğu; ALL'nin tibial translasyonu ve iç rotasyonu önlemedeki potansiyel rolünü ortaya koymuştur. Böylelikle bazı durumlarda ÖÇBR cerrahisinin tek başına dizin normal kinematiğini sağlayamayacağını desteklemektedir. ${ }^{[42-46]}$

Kesin kanıtları olmamakla beraber; ameliyat öncesi yüksek dereceli pivot kayması olan veya anatomik rekonstrüksiyonu takiben reziduel pivot kayması olan ÖÇB yaralanmalarında, altta yatan ciddi hiperlaksitesi olan genç aktif hastalarda, kontakt pivot sporlara dönecek sporcularda, Segond kırığı varlığında ve revizyon cerrahilerinde ALL akılda tutulmalıdır. ${ }^{[45,47]}$

Anterolateral destek prosedürleri geleneksel lateral ekstra-artiküler tenodez ve modern ALL rekonstrüksiyonu şeklinde yapılmaktadır. Bu iki teknik ile ilgili yayınlanan yeni bir derlemede; lateral ekstra-artiküler 
tenodez yapılan dizlerde daha fazla reziduel instabilite görüldügüu bununla beraber rotasyonel stabilite ve klinik sonuçların benzer olduğu vurgulanmıştır. ${ }^{[8]}$ ALL rekonstrüksiyonunun lateral ekstra-artiküler tenodeze göre daha fazla eklem hareket kısıtıılığına yol açtığını gösteren çalışmalar mevcut olsa da şu anki veriler ile bir tekniğin diğerine göre klinik üstünlüğü henüz kanıtlanmamıştır. ${ }^{[49]}$

\section{TAMIR VEYA REKONSTRÜKSIYONDA BIYOLOJIK AJANLAR}

Hem ÖÇBR'de hem de kısmı yırtıkların konservatif tedavisinde biyolojik ajanlara artan ilgi mevcuttur. Bu çalışmalar iki maddeye odaklanmıştır: trombositten zengin plazma (PRP) ve mezenkimal kök hücreler. ${ }^{[50]}$

PRP, ortopedide yoğun şekilde kullanılan bir ajan olmasına rağmen ÖÇB tamiri veya ÖÇBR üzerindeki rolü ve etkisi konusunda fikir birliği yoktur. Bununla birlikte, bir dizi çalışma PRP'nin zaman içinde greft olgunlaşmasını destekleyebileceğini düşündürmektedir, ancak bu halen tartışmalıdır ve bu bulguyu desteklemeyen çalışmalar da vardır. ${ }^{[1,52]}$ PRP'nin kemik-greft entegrasyonuna veya kemik tünelin genişlemesinin önlenmesine yönelik kanıtlanmış bir faydası yoktur. ${ }^{[50]}$ PRP'nin kısmi yırtıklarda kullanımı da halen tam olarak anlaşılamamıştır ve henüz yeterli çalışma yoktur. Son zamanlarda yapılan köpek araştırmaları, PRP'nin ağrıyı azaltabileceğini, fonksiyonu iyileştirebileceğini düşündürmektedir ve serum fizyolojik enjeksiyonuna kıyasla tamir sonrası histolojik muayenede azalmış sinovit oranları gösterilmiştir. ${ }^{[53]}$ Yapılan yeni bir derleme kanıt düzeyi Evre 1 olan çalışmaların; greft iyileşmesini arttırmak, donör bölge morbiditesini azaltmak, ameliyat sonrası ağrıyı azaltmak veya ÖÇBR'yi takiben fonksiyonel sonuçları iyileştirmek için PRP kullanımını desteklemediği göstermiştir. ${ }^{[54]}$

Rejeneratif tıpta mezenkimal kök hücrelerinin kullanımına büyük ilgi gösterilmiştir. Ancak ÖÇB yaralanmalarının tedavisindeki rolleri oldukça tartışmalıdır ve iyi anlaşıımamıştır.

2014 yılında Silva ve ark.'nın yaptığı çalışma; erişkin kemik iliği kök hücrelerinin ÖÇBR'de greft-kemik iyileşmesini hızlandırmadığını göstermiştir. ${ }^{[55]}$

Birkaç çalışmada farklı dokulardaki mezenkimal kök hücrelerin karşılaştırmalı potansiyeli değerlendirilmiştir. 2017 yılında Cuti ve ark., in vitro olarak kas dokusundan elde edilen mezenkimal kök hücrelerin, kemik-tendon entegrasyonunu ve greft ligamentizasyonunu HT'nin kendisinden üretilmiş olanlara göre daha fazla destekleme kapasitesine sahip olduğu sonucuna varmıştır. Elde edilen HT otogreftinden kalan tüm kasları sıyırmak yerine, tendonda bırakılan bir miktar kasın daha iyi greft olgunlaşması ve entegrasyonu sağlayabileceğini ileri sürmüşlerdir. Diğer bir çalışma HT'den üretilen kök hücreler ile hastanın kendi ön çapraz bağından üretilenlerin potansiyelini karşılaştırmıştır. Ön çapraz bağdan üretilen kök hücrelerin HT greftinden çok daha yüksek potansiyele sahip oldukları sonucuna varmışlardır. Bununla beraber dış uyaranların HT otogreftinin olgunlaşması ve daha normal ligamentöz özellik göstermesi için önemli olduğunu ileri sürmüşlerdir. ${ }^{[56]}$

Unutulmamalı ki PRP ve kök hücrelerin kullanımını araştıran çalışmalar, değişken hasta biyolojisi, preperatı elde etme, hazırlama ve uygulama tekniklerinin heterojenliği açısından kısıtlamalara tabidir. Bununla birlikte, klinik çalışmalar sadece yakın zamanda mevcuttur ve göreceli olarak az sayıdadır. Kök hücrelerin ligament onarımı veya rekonstrüksiyonunda rutin kullanılabilmesi için kanıt düzeyi yüksek çalışmalara ihtiyaç vardır.

\section{AMELIYAT ÖNCESI VE SONRASI REHABILITASYON}

ÖÇBR'nin zamanlaması rehabilitasyon sonuçlarını etkileyebilir, çünkü erken dönem ÖÇBR kuadriseps iyileşmesinde gecikme ve eklem hareket aralığında azalma ile ilişkilendirilmiştir. Birkaç çalışmada, gecikmiş rekonstrüksiyona (yaralanma sonrası 8.-21. günler) kıyasla erken ÖÇBR'de (yaralanma sonrası 0-7. gün) kuadriseps mukavemetinin yanı sıra terminal diz ekstansiyonunda önemli derecede kayıp olduğunu göstermektedir. ${ }^{[11]}$ Ameliyat öncesi rehabilitasyon, kuadriseps kuvvetinin ve diz hareket açıklığının korunmasına odaklanmalıdır, çünkü bu parametrelerin her ikisinde de bulunan eksikler daha zayıf fonksiyonel sonuçlarla ilişkilidir. ${ }^{[57]}$

ÖÇB yaralanmalarının yapılandırılmış rehabilitasyonu, ister rekonstrüksiyonla, ister sadece rehabilitasyon ile konservatif tedavi edilmiş olan hastalar için benzerdir. Genel olarak rehabilitasyon programları arasında kriyoterapi (buz), yerçekimi destekli hareket veya sürekli pasif hareket (bir makine ile sürekli mekanik hareket), koruyucu destek, elektrik nöromüsküler stimülasyon ve güçlendirmeyi amaçlayan egzersizler (yani izometrik, izotonik ve izokinetik) bulunur. ${ }^{[6]}$ Konservatif veya cerrahi müdahalenin bir bileşeni olarak kullanılan rehabilitasyonda tipik olarak akut, iyileşme ve fonksiyonel fazlardan oluşan üç aşamalı bir program kullanır. Akut aşama hem akut yaralanmayı takiben hem de ameliyat sonrasında hemen uygulanır ve hareket aralığını eski haline getirmeyi, kuadriseps gücünü korumayı ve enflamasyonu azaltmayı amaçlar. İyileşme aşaması, alt ekstremite kas kuvvetini ve fonksiyonel stabiliteyi 
iyileştirmek amacıyla uygulanır ve tipik olarak 3-6 hafta sürer. Fonksiyonel evre genellikle yaralanma sonrası veya ameliyat sonrası 6 . haftada başlar ve hastayı önceki aktivite düzeylerine geri döndürmeye yöneliktir. Fonksiyonel evre, yeniden yaralanma riskini azaltma çabalarını da içermelidir. ${ }^{[6]}$

Rehabilitasyon tipik olarak bu üç fazlı programı takip etse de, en etkili rehabilitasyon protokolü hakkında çok az fikir birliği vardır. Benzer şekilde, spora geri dönüş için kabul edilebilir zaman çerçevesi konusunda net bir fikir birliği yoktur. Spora geri dönüşte acele edilmesi, artmış greft yetmezliği riski ve kontralateral ÖÇB yaralanması ile ilişkilendirilmiştir. ${ }^{[3]} \mathrm{Bu}$ nedenle, son eğilimler, 8-12 ay veya daha uzun sürede spora geri dönüş olacağını dikkate alan yavaşlatılmış bir rehabilitasyon protokolünü desteklemektedir. ${ }^{[10]}$

Standartlaştırılmış bir spora geri dönüş protokolü mevcut olmasa da, çalışmalar bir sporcu için belirli klinik kriterleri karşıladığında spora geri dönüusün güvenli olduğunu göstermektedir;

Bu kriterler:

1. Ameliyat süresi (8 ila $12+$ ay)

2. Ağrı ve efüzyon yokluğu

3. Kontralateral (karşı) uzuvla karşılaştırılabilir diz hareket aralığı

4. Negatif Lachman veya pivot kayma testi

5. Kontralateral ekstremiteye göre $>\% 85-90$ oranında atlama testi performansı

6. Dinamik valgus olmadan düşey-dikey zıplama gibi zıplama ve iniş görevleri

Üzerinde yoğunlaşılan bir diğer konu ise kan akışının kısıtlanarak (blood flow restriction) yapıldığı rehabilitasyon programıdır. Bu programda ekstremiteye turnike uygulaması ile arteriyel kan girişi korunurken venöz çıkış kısıtlanır. Böylece düşük dirençli egzersizler sırasında kas hücrelerine oksijen iletimi azalır. İndüklenen anaerobik ortamın protein sentezini arttırarak kas hipertrofisine sebep olduğu bildirilmiştir. ${ }^{[58]}$

Bu konu ile standardize edilmiş ve uzun süreli takiplerin olduğu klinik çalışmalara ihtiyaç vardır. ${ }^{[59]}$

\section{REVIZYON ÖN ÇAPRAZ BAĞ REKONSTRÜKSIYYONU}

Yetişkinler için \%14'e ve 18 yaşın altındaki erkekler için \%28'e varan başarısızlık oranları bildirildiği için bireyi ÖÇB yaralanmasına yatkın hale getiren faktörleri anlamak zorunludur. ${ }^{[60]}$

Schilaty ve ark. 20 yıllık bir süre içinde, bireylerin \%6'sında ikinci bir ÖÇB rüptürü olduğunu ve bunların \%67'sinin kontralateral dizde olduğunu göstermiştir. Ayrıca 20 yaşın altındaki kadınlarda daha yüksek başarısızlık oranlarının daha sıklıkla HT otogreftinin kullanımıyla ilişkili olduğunu bildirmiştir. ${ }^{[61]}$

Ho ve ark. 12 yıllık çalışma sürelerinde pediatrik/ ergen popülasyonunda $\% 9,6$ başarısızlık oranı ve $\% 8$ kontralateral ÖÇB rüptürü oranı bildirmiştir. BPTB greftlerinin en düşük başarısızlık oranına sahip olduğunu ve greft seçiminin çok değişkenli analizde başarısızlığın en güçlü belirleyicisi olduğunu bildirmişlerdir. ${ }^{[62]}$

Birden fazla çalışma, artmış yaşın revizyon ÖÇBR'ye karşı koruyucu bir faktör olduğunu ve primer ÖÇBR ile revizyon ÖÇBR arasındaki ortalama sürenin literatürde 1,5 ile 3,5 yıl arasında değiştiğini bildirmiştir. ${ }^{[63,64]}$ Allogreft kullanıldığında artmış greft ışınlaması (>1,8 Mrad) gibi bazı greft işleme teknikleri ile daha yüksek revizyon oranları bildirilmiştir. ${ }^{[65]}$

ÖÇBR sırasında eşzamanlı menisküs lezyonları, meniskokapsüler ayrışmalar ve anormal kemik morfolojisinin varlığı da önemlidir. Parkinson ve ark., menisküs lezyonlarının (medial>lateral) tek demet anatomik ÖÇBR'de greft yetmezliği ile ilişkili en önemli risk faktörü olduğunu, anatomik olmayan femoral tünel yerleşiminin ve genç hasta yaşının başarısızlık için ek risk faktörleri olduğunu saptamıştır. ${ }^{[66]}$

Artmış lateral tibial posterior eğim (LPTE), bir dizi çalışmada ÖÇB rüptürüne yatkınlıkla ilişkilendirilmiştir. Christensen ve ark., LPTE ile revizyon oranlarının artması arasında bir ilişki olduğunu bildirmiş, erken başarısızlık grubunda LPTE ortalamasının $8,4^{\circ}$ iken kontrol gruplarında $6,5^{\circ}$ olduğunu göstermiştir. Rerüptür oranlarının LPTE derecesi ile doğrudan ilişkili olduğunu ve bunun istatistiksel olarak anlamlı olduğunu bildirmişlerdir. ${ }^{[67]}$ Arun ve ark. LPTE'yi azaltmak için ÖÇBR sırasında $5^{\circ}$ üstü düzeltme uygulanan bireylerde anlamlı olarak daha iyi fonksiyonel skorlar elde etmişlerdir. ${ }^{[68]}$ Ancak Dean ve ark., açık kama proksimal tibial osteotomi kullanımının, posteromedial olarak yerleştirilen anterior açılı osteotomi plağı ile birlikte sagittal tibial eğimi azaltmada başarısız olduğunu bildirmiştir. Mevcut osteotomi plaklarının tasarım ve tekniklerinin sagittal düzlem tibial eğimi azaltmada etkili olmadığı sonucuna varmışlardır. ${ }^{[69]}$

Galla ve ark. yapmış oldukları retrospektif çalışmada; genç yaşın $(<21)$ sonraki (revizyon veya kontralateral) ÖÇBR için en büyük risk faktörü olduğunu bulmuştur. Ayrıca, erişkin hastalarda çalışanların tazminat beklentisinin sonraki (revizyon veya kontralateral) ÖÇBR için bağımsız bir risk faktörü olduğunu göstermişlerdir. ${ }^{[70]}$

Liechti ve ark. tarafından yapılan sistematik bir derleme, tekrar revizyon vakalarında görülen menisküs ve kıkırdak patolojileri gibi ek durumların primer 
vakalara göre daha yüksek oranda olduğunu göstermiştir. ÖÇB yaralanması tedavisinde başarısızlık riskini ve sonraki revizyon oranlarını en aza indirmek için eşlik eden patolojileri göz ardı etmemek gerektiğini vurgulamışlardır. ${ }^{60]}$

2020 yılındaki derlemelerden biri olan Rahardja ve ark.'nın çalışmasında genç yaşın revizyon riskini arttıran en önemli risk faktörü olduğu bildirilmiştir. Cinsiyet, vücut kitle endeksi, etnik köken, eşlik eden yaralanmalar ve yapılan sporun çeşidi diğer risk faktörleri olarak sıralanmıştır. ${ }^{[71]}$

Son olarak unutulmaması gereken bir diğer konu ise rehabilitasyon sürecinde sağlam dizin göz ardı edilmemesidir. Öyle ki Grassi ve ark., çok güncel çalışmalarında 10 yıl takip ettikleri hastaların \%10,7'sinde ameliyat olan taraflarında tekrar bir yaralanma gerçekleştiğini göstermişlerdir. Ayrıca bu hastaların karşı dizlerinde ÖÇBR riski aynı taraf ÖÇBR revizyonu riskine göre daha fazladır. Özellikle genç ve aktif hastalarda bu risk \%40'a kadar ulaşmıştır. ${ }^{[72]}$

Tekrar revizyon vakaları henüz iyi dökümante edilememiştir ve çoklu revizyonlar için risk faktörleri tam olarak anlaşılamamıştır. Hastaları ameliyat öncesi olası riskler hakkında bilgilendirirken re-rüptür konusunda da uyarmak gerekmektedir.

\section{ÖN ÇAPRAZ BAĞ YARALANMASINI KORUYUCU YÖNTEMLER}

Son çalışmalar sadece ÖÇB yaralanması için anatomik ve biyomekanik risk faktörlerini daha iyi anlamakla kalmayıp, aynı zamanda değiştirilebilir risk faktörlerini de incelemeyi amaçlamıştır.

Nöromüsküler kontrolün yaralanma riskinde önemli bir rol oynadığı düşünülmektedir ve en çok değiştirilebilir risk faktörü olarak tanımlanmıştır. Hewett ve ark. ÖÇB yaralanma riskinin arttığı dört nöromüsküler dengesizlik tespit etmişlerdir: bağ hakimiyeti, kuadriseps hakimiyeti, bacak hakimiyeti ve gövde hakimiyeti. ${ }^{[73]}$ Alt ekstremitede artmış dinamik valgus pozisyonu ve abduksiyon yükleri, kadın atletlerde artmış ÖÇB yaralanması riski ile ilişkilendirilmiştir. Kadınlarda nöromüsküler antrenmanın, laboratuvar ortamında dinamik diz stabilitesini arttırdığı gösterilmiştir ve kadın atletlerde non-kontakt ÖçB yaralanması insidansını azaltmaktadır. ${ }^{[74]}$

Nöromüsküler antrenman, ÖÇB'yi performans sırasında yüksek yüklerinden korur. ${ }^{[73]}$

Gluteal kaslar ve hamstringler gibi posterior zincir kas grubunun güçlendirilmesine vurgu yapılarak, frontal düzlem hareketinin ve nöromüsküler kontrolün geliştirerek ÖÇB'ye olan yükün azaltılabiliceği bildirilmiştir. ${ }^{[75]}$
Tarama ve önleme programlarının kullanımı için bir dizi seçenek mevcuttur, ancak tipik hareket görüntüleme sistemleri pahalıdır ve birden fazla kamera ve/ veya çoklu işaretleyici kullanılmasını gerektirir. Bu sorunun potansiyel bir çözümü, nispeten daha az pahalı olan ve çalışma konularına işaretçilerin yerleştirilmesini gerektirmeyen Microsoft Kinect SDK'nin kullanılmasıdır. ${ }^{[76,77]}$

2014 yilında Gray ve ark., Kinect hareket yakalama sistemi ile "altın standart" Vicon sistemi arasında mükemmel korelasyon değerleri bulmuştur. 2016 yılında daha büyük ölçekli bir modelde Sherman ve ark., 180 sağlıklı lise sporcusunu değerlendirmişlerdir. Sistemin güvenli, verimli ( $1,5 \mathrm{dk} /$ atlet değerlendirmesi) ve sporcuyu ÖÇB yaralanması riskine sokan bir pozisyon olan düşey dikey sıçrama testi sırasında dinamik valgus tespitinde etkili olabileceği sonucuna varmışlardır. ${ }^{[77]}$ Birden fazla çalışma, Kinect sisteminin, ÖÇB yaralanması riski taşıyan bireyleri tanımlamak için dinamik tarama ve hedefli müdahale için mümkün olduğunu göstermiştir. ${ }^{[76,77]}$

Gelecekteki araştırmalar, yüksek riskli sporcuların daha iyi tanımlanmasını ve uyarlanmış müdahalelerin geliştirilmesine izin vermek için değiştirilebilir risk faktörlerinin ve patolojik biyomekaniğin daha hassas ve verimli bir şekilde taranmasını amaçlamalıdır.

\section{SONUÇ}

ÖÇB yaralanmalarının tedavisi sürekli kendini güncelleyen ve gelişen bir alandır. Çeşitli dönemlerde farklı yaklaşımlar popülarize olabilmektedir. Zamanla doğal diz kinematiği, ligaman iyileşmesinin temeli ve ÖÇB cerrahisindeki başarısızlığının başlıca nedenleri daha iyi anlaşılacaktır. Bununla beraber cerrahi tekniklerin ilerlemesi ve yaralanma önleyici sistemlerin gelişmesiyle birlikte tedavi stratejileri değişebilecektir. Değişmeyecek tek şey ÖÇB'nin her yönüyle spor ortopedistlerinin hayatlarının bir parçası olacağıdır.

\section{KAYNAKLAR}

1. Kiapour AM, Murray MM. Basic science of anterior cruciate ligament injury and repair. Bone Joint Res 2014;3(2):20-31. Crossref

2. Kim S, Bosque J, Meehan JP, Jamali A, Marder R. Increase in outpatient knee arthroscopy in the United States: a comparison of National Surveys of Ambulatory Surgery, 1996 and 2006. J Bone Joint Surg Am 2011;93(11):994-1000. Crossref

3. Ellman MB, Sherman SL, Forsythe B, LaPrade RF, Cole BJ, Bach BRJr. Return to play following anterior cruciate ligament reconstruction. J Am Acad Orthop Surg 2015;23(5):283-96. Crossref

4. Atarod M, Frank CB, Shrive NG. Increased meniscal loading after anterior cruciate ligament transection in vivo: a longitudinal study in sheep. Knee 2015;22(1):11-7. Crossref 
5. Ajuied A, Wong F, Smith C, Norris M, Earnshaw P, Back D, Davies A. Anterior cruciate ligament injury and radiologic progression of knee osteoarthritis: a systematic review and metaanalysis. Am J Sports Med 2014;42(9):2242-52. Crossref

6. Monk AP, Davies LJ, Hopewell S, Harris K, Beard DJ, Price AJ. Surgical versus conservative interventions for treating anterior cruciate ligament injuries. Cochrane Database Syst Rev 2016;4:CD011166. Crossref

7. Frobell RB, Roos HP, Roos EM, Roemer FW, Ranstam J, Lohmander LS. Treatment for acute anterior cruciate ligament tear: five year outcome of randomised trial. BMJ 2013;346(1):f232. Crossref

8. Gföller $\mathrm{P}$, Abermann $\mathrm{E}$, Runer A, Hoser $\mathrm{C}$, Pflüglmayer $\mathrm{M}$, Wierer G, Fink C. Non-operative treatment of ACL injury is associated with opposing subjective and objective outcomes over 20 years of follow-up. Knee Surg Sports Traumatol Arthrosc 2019;27(8):2665-71. Crossref

9. van Yperen DT, Reijman M, van Es EM, Bierma-Zeinstra SMA, Meuffels DE. Twenty-Year Follow-up Study Comparing Operative Versus Nonoperative Treatment of Anterior Cruciate Ligament Ruptures in High-Level Athletes. Am J Sports Med 2018;46(5):1129-36. Crossref

10. Temponi EF, de Carvalho Júnior LH, Sonnery-Cottet B, Chambat P. Partial tearing of the anterior cruciate ligament: diagnosis and treatment. Rev Bras Ortop 2015;50(1):9-15. Crossref

11. Colombet P, Dejour D, Panisset JC, Siebold R; French Arthroscopy Society. Current concept of partial anterior cruciate ligament ruptures. Orthop Traumatol Surg Res 2010;96(8 Suppl):S109-18. Crossref

12. Fayard JM, Sonnery-Cottet B, Vrgoc G, O'Loughlin P, de Mont Marin GD, Freychet B, Vieira TD, Thaunat M. Incidence and Risk Factors for a Partial Anterior Cruciate Ligament Tear Progressing to a Complete Tear After Nonoperative Treatment in Patients Younger Than 30 Years. Orthop J Sports Med 2019;7(7):2325967119856624. Crossref

13. Costa-Paz M, Ayerza MA, Tanoira I, Astoul J, Muscolo DL. Spontaneous healing in complete ACL ruptures: a clinical and MRI study. Clin Orthop Relat Res 2012;470(4):979-85. Crossref

14. Barrack RL, Buckley SL, Bruckner JD, Kneisl JS, Alexander $\mathrm{AH}$. Partial versus complete acute anterior cruciate ligament tears. The results of nonoperative treatment. J Bone Joint Surg Br 1990;72-B(4):622-4. Crossref

15. Buda R, Baldassarri M, Perazzo L, Ghinelli D, Faldini C. The biological respect of the posterolateral bundle in $A C L$ partial injuries. Retrospective analysis of 2 different surgical management of ACL partial tear in a population of highdemanding sport patients. Eur J Orthop Surg Traumatol 2019;29(3):651-8. Crossref

16. Gipsman AM, Trasolini N, Hatch GFR 3rd. Primary Anterior Cruciate Ligament Single-Bundle Repair With Augmentation for a Partial Anterior Cruciate Ligament Tear. Arthrosc Tech 2018;7(4):e367-72. Crossref

17. Araujo $\mathrm{PH}$, Asai $\mathrm{S}$, Pinto $\mathrm{M}$, Protta $\mathrm{T}$, Middleton $\mathrm{K}$, LindeRosen M, Irrgang J, Smolinski P, Fu FH. ACL Graft Position Affects in Situ Graft Force Following ACL Reconstruction. J Bone Joint Surg Am 2015;97(21):1767-73. Crossref

18. Stannard JP, Sherman SL, Cook JL. Soft tissues about the knee. In: Grauer JN, editor. AAOS Orthopaedic Knowledge Update 12, Chp. 36; 2017. pp.1-13.

19. Chen H, Tie K, Qi Y, Li B, Chen B, Chen L. Anteromedial versus transtibial technique in single-bundle autologous hamstring $\mathrm{ACL}$ reconstruction: a meta-analysis of prospective randomized controlled trials. J Orthop Surg Res 2017;12(1):167. Crossref
20. Tibor L, Chan PH, Funahashi TT, Wyatt R, Maletis GB, Inacio MC. Surgical Technique Trends in Primary ACL Reconstruction from 2007 to 2014. J Bone Joint Surg Am 2016;98(13):1079-89. Crossref

21. Paschos NK, Howell SM. Anterior cruciate ligament reconstruction: principles of treatment. EFORT Open Rev 2017;1(11):398-408. Crossref

22. Fu FH, Jordan SS. The lateral intercondylar ridge --a key to anatomic anterior cruciate ligament reconstruction. J Bone Joint Surg Am 2007;89(10):2103-4. Crossref

23. Tiamklang $T$, Sumanont S, Foocharoen $T$, Laopaiboon M. Double-bundle versus single-bundle reconstruction for anterior cruciate ligament rupture in adults. Cochrane Database Syst Rev 2012;11:CD008413. Crossref

24. Chen H, Chen B, Tie K, Fu Z, Chen L. Single-bundle versus double-bundle autologous anterior cruciate ligament reconstruction: a meta-analysis of randomized controlled trials at 5-year minimum follow-up. J Orthop Surg Res 2018;13(1):50. Crossref

25. Onggo JR, Nambiar M, Pai V. Fixed- Versus AdjustableLoop Devices for Femoral Fixation in Anterior Cruciate Ligament Reconstruction: A Systematic Review. Arthroscopy 2019;35(8):2484-98. Crossref

26. Houck DA, Kraeutler MJ, McCarty EC, Bravman JT. FixedVersus Adjustable-Loop Femoral Cortical Suspension Devices for Anterior Cruciate Ligament Reconstruction: A Systematic Review and Meta-analysis of Biomechanical Studies. Orthop J Sports Med 2018;6(10):2325967118801762. Crossref

27. Duchman KR, Lynch TS, Spindler KP. Graft Selection in Anterior Cruciate Ligament Surgery: Who gets What and Why? Clin Sports Med 2017;36(1):25-33. Crossref

28. Widner M, Dunleavy M, Lynch S. Outcomes Following ACL Reconstruction Based on Graft Type: Are all Grafts Equivalent? Curr Rev Musculoskelet Med 2019;12(4):460-5. Crossref

29. Cavaignac E, Coulin B, Tscholl P, Nik Mohd Fatmy N, Duthon V, MenetreyJ. Is Quadriceps Tendon Autograft a Better Choice Than Hamstring Autograft for Anterior Cruciate Ligament Reconstruction? A Comparative Study with a Mean Follow-up of 3,6 Years. Am J Sports Med 2017;45(6):1326-32. Crossref

30. Wang S, Zhang C, Cai Y, Lin X. Autograft or Allograft? Irradiated or Not? A Contrast Between Autograft and Allograft in Anterior Cruciate Ligament Reconstruction: A Meta-analysis. Arthroscopy 2018;34(12):3258-65. Crossref

31. Wang HD, Gao SJ, Zhang YZ. Hamstring Autograft Versus Hybrid Graft for Anterior Cruciate Ligament Reconstruction: A Systematic Review. Am J Sports Med 2020;48(4):1014-22. Crossref

32. Belk JW, Kraeutler MJ, Houck DA, Smith JR, McCarty EC. Comparing Hamstring Autograft with Hybrid Graft for Anterior Cruciate Ligament Reconstruction: A Systematic Review. Arthroscopy 2020;36(4):1189-201. Crossref

33. Kösters C, Glasbrenner J, Spickermann L, Kittl C, Domnick C, Herbort M, Raschke MJ, Schliemann B. Repair with Dynamic Intraligamentary Stabilization Versus Primary Reconstruction of Acute Anterior Cruciate Ligament Tears: 2-Year Results from a Prospective Randomized Study. Am J Sports Med 2020;48(5):1108-16.

34. van der List JP, DiFelice GS. Primary repair of the anterior cruciate ligament: A paradigm shift. Surgeon 2017;15(3):161-8. Crossref

35. Malahias MA, Chytas D, Nakamura K, Raoulis V, Yokota M, Nikolaou VS. A Narrative Review of Four Different New Techniques in Primary Anterior Cruciate Ligament Repair: "Back to the Future" or Another Trend? Sports Med Open 2018;4(1):37. Crossref 
36. DiFelice GS, van der List JP. Arthroscopic Primary Repair of Proximal Anterior Cruciate Ligament Tears. Arthrosc Tech 2016;5(5):e1057-61. Crossref

37. Dabis J, Yasen SK, Foster AJ, Pace JL, Wilson AJ. Paediatric proximal $A C L$ tears managed with direct $A C L$ repair is safe, effective and has excellent short-term outcomes. Knee Surg Sports Traumatol Arthrosc 2020. Crossref

38. Nwachukwu BU, Patel BH, Lu Y, Allen AA, Williams RJ 3rd. Anterior Cruciate Ligament Repair Outcomes: An Updated Systematic Review of Recent Literature. Arthroscopy 2019;35(7):2233-47. Crossref

39. Houck DA, Kraeutler MJ, Belk JW, Goode JA, Mulcahey MK, Bravman JT. Primary Arthroscopic Repair of the Anterior Cruciate Ligament: A Systematic Review of Clinical Outcomes. Arthroscopy 2019;35(12):3318-27. Crossref

40. Kandhari V, Vieira TD, Ouanezar H, Praz C, Rosenstiel N, Pioger C, Franck F, Saithna A, Sonnery-Cottet B. Clinical Outcomes of Arthroscopic Primary Anterior Cruciate Ligament Repair: A Systematic Review from the Scientific Anterior Cruciate Ligament Network International Study Group. Arthroscopy 2020;36(2):594-612. Crossref

41. Claes S, Vereecke E, Maes M, Victor J, Verdonk P, Bellemans $\mathrm{J}$. Anatomy of the anterolateral ligament of the knee. J Anat 2013;223(4):321-8. Crossref

42. Imbert P, Lutz C, Daggett $M$, Niglis L, Freychet B, Dalmay F, Sonnery-Cottet B. Isometric characteristics of the anterolateral ligament of the knee: A cadaveric navigation study. Arthroscopy 2016;32(10):2017-24. Crossref

43. Ibrahim SA, Shohdy EM, Marwan Y, Ramadan SA, Almisfer AK, Mohammad MW, Abdulsattar WS, Khirat S. Anatomic reconstruction of the anterior cruciate ligament of the knee with or without reconstruction of the anterolateral ligament: $A$ randomized clinical trial. Am J Sports Med 2017;45(7):155866. Crossref

44. Patel RM, Brophy RH. Anterolateral ligament of the knee: Anatomy, function, imaging, and treatment. Am J Sports Med 2018;46(1):217-23. Crossref

45. Musahl V, Getgood A, Neyret P, Claes S, Burnham JM, Batailler C, Cottet BS, Williams A, Amis A, Zaffagnini S, Karlsson J. Contributions of the anterolateral complex and the anterolateral ligament to rotatory knee stability in the setting of ACL injury: A roundtable discussion. Knee Surg Sports Traumatol Arthrosc 2017;25(4):997-1008. Crossref

46. Stentz-Olesen K, Nielsen ET, de Raedt S, Jørgensen PB, Sørensen OG, Kaptein B, Søballe K, Stilling M. Reconstructing the anterolateral ligament does not decrease rotational knee laxity in ACL-reconstructed knees. Knee Surg Sports Traumatol Arthrosc 2017;25(4):1125-31. Crossref

47. Ariel de Lima D, Helito CP, Lima FRA, Leite JAD. Surgical indications for anterior cruciate ligament reconstruction combined with extra-articular lateral tenodesis or anterolateral ligament reconstruction. Rev Bras Ortop 2018;53(6):661-7. Crossref

48. Ra HJ, Kim JH, Lee DH. Comparative clinical outcomes of anterolateral ligament reconstruction versus lateral extraarticular tenodesis in combination with anterior cruciate ligament reconstruction: systematic review and meta-analysis. Arch Orthop Trauma Surg 2020. Crossref

49. Mathew M, Dhollander A, Getgood A. Anterolateral Ligament Reconstruction or Extra-Articular Tenodesis: Why and When? Clin Sports Med 2018;37(1):75-86. Crossref

50. Di Matteo B, Loibl M, Andriolo L, Filardo G, Zellner J, Koch $\mathrm{M}$, Angele P. Biologic agents for anterior cruciate ligament healing: A systematic review. World J Orthop 2016;7(9):592603. Crossref
51. Komzák M, Hart R, Šmíd P, Puskeiler M, Jajtner P. The effect of platelet-rich plasma on graft healing in reconstruction of the anterior cruciate ligament of the knee joint: prospective study. Acta Chir Orthop Traumatol Cech 2015;82(2):135-9.

52. Andriolo L, Di Matteo B, Kon E, Filardo G, Venieri G, Marcacci M. PRP Augmentation for ACL Reconstruction. Biomed Res Int 2015;2015:371746. Crossref

53. Cook JL, Smith PA, Bozynski CC, Kuroki K, Cook CR, Stoker AM, Pfeiffer FM. Multiple injections of leukoreduced platelet rich plasma reduce pain and functional impairment in a canine model of $A C L$ and meniscal deficiency. J Orthop Res 2016;34(4):607-15. Crossref

54. Davey MS, Hurley ET, Withers D, Moran R, Moran CJ. Anterior Cruciate Ligament Reconstruction with Platelet-Rich Plasma: A Systematic Review of Randomized Control Trials. Arthroscopy 2020;36(4):1204-10. Crossref

55. Silva A, Sampaio R, Fernandes R, Pinto E. Is there a role for adult non-cultivated bone marrow stem cells in $A C L$ reconstruction? Knee Surg Sports Traumatol Arthrosc 2014;22(1):66-71. Crossref

56. Cuti T, Antunovic M, Marijanovic I, Ivkovic A, Vukasovic A, Matic I, Pecina M, Hudetz D. Capacity of muscle derived stem cells and pericytes to promote tendon graft integration and ligamentization following anterior cruciate ligament reconstruction. Int Orthop 2017;41(6):1189-98. Crossref

57. Grindem H, Granan LP, Risberg MA, Engebretsen L, SnyderMackler L, Eitzen I. How does a combined preoperative and postoperative rehabilitation programme influence the outcome of ACL reconstruction 2 years after surgery? A comparison between patients in the Delaware-Oslo ACL Cohort and the Norwegian National Knee Ligament Registry. BrJ Sports Med 2015;49(6):385-9. Crossref

58. Gundermann DM, Walker DK, Reidy PT, Borack MS, Dickinson JM, Volpi E, Rasmussen BB. Activation of mTORC1 signaling and protein synthesis in human muscle following blood flow restriction exercise is inhibited by rapamycin. Am J Physiol Endocrinol Metab 2014;306(10):E1198-204. Crossref

59. LuY, Patel BH, Kym C, Nwachukwu BU, Beletksy A, Forsythe B, Chahla J. Perioperative Blood Flow Restriction Rehabilitation in Patients Undergoing ACL Reconstruction: A Systematic Review. OrthopJ Sports Med 2020;8(3):2325967120906822. Crossref

60. Liechti DJ, Chahla J, Dean CS, Mitchell JJ, Slette E, Menge TJ, LaPrade RF. Outcomes and Risk Factors of Rerevision Anterior Cruciate Ligament Reconstruction: A Systematic Review. Arthroscopy 2016;32(10):2151-9. Crossref

61. Schilaty ND, Bates NA, Sanders TL, Krych AJ, Stuart MJ, Hewett TE. Incidence of Second Anterior Cruciate Ligament Tears (1990-2000) and Associated Factors in a Specific Geographic Locale. Am J Sports Med 2017;45(7):1567-73. Crossref

62. Ho B, Edmonds EW, Chambers HG, Bastrom TP, Pennock AT. Risk Factors for Early ACL Reconstruction Failure in Pediatric and Adolescent Patients: A Review of 561 Cases. J Pediatr Orthop 2018;38(7):388-92. Crossref

63. Yabroudi MA, Björnsson H, Lynch AD, Muller B, Samuelsson K, Tarabichi M, Karlsson J, Fu FH, Harner CD, Irrgang JJ. Predictors of Revision Surgery After Primary Anterior Cruciate Ligament Reconstruction. Orthop J Sports Med 2016;4(9):2325967116666039. Crossref

64. Ponce BA, Cain EL Jr, Pflugner R, Fleisig GS, Young BL, Boohaker HA, Swain TA, Andrews JR, Dugas JR. Risk Factors for Revision Anterior Cruciate Ligament Reconstruction. J Knee Surg 2016;29(4):329-36. Crossref 
65. Tejwani SG, Chen J, Funahashi $\Pi$, Love R, Maletis GB. Revision Risk After Allograft Anterior Cruciate Ligament Reconstruction: Association with Graft Processing Techniques, Patient Characteristics, and Graft Type. Am J Sports Med 2015;43(11):2696-705. Crossref

66. Parkinson B, Robb C, Thomas M, Thompson P, Spalding T. Factors That Predict Failure in Anatomic Single-Bundle Anterior Cruciate Ligament Reconstruction. Am J Sports Med 2017;45(7):1529-36. Crossref

67. Christensen JJ, Krych AJ, Engasser WM, Vanhees MK, Collins MS, Dahm DL. Lateral Tibial Posterior Slope Is Increased in Patients with Early Graft Failure After Anterior Cruciate Ligament Reconstruction. Am J Sports Med 2015;43(10):2510-4. Crossref

68. Arun GR, Kumaraswamy V, Rajan D, Vinodh $K$, Singh AK, Kumar P, Chandrasekaran K, Santosh S, Kishore C. Longterm follow up of single-stage anterior cruciate ligament reconstruction and high tibial osteotomy and its relation with posterior tibial slope. Arch Orthop Trauma Surg 2016;136(4):505-11. Crossref

69. Dean CS, Chahla J, Matheny LM, Cram TR, Moulton SG, Dornan GJ, Mitchell JJ, LaPrade RF. Posteromedially placed plates with anterior staple reinforcement are not successful in decreasing tibial slope in opening-wedge proximal tibial osteotomy. Knee Surg Sports Traumatol Arthrosc 2017;25(12):3687-94. Crossref

70. Gallo MC, Bolia IK, Jalali O, Rosario S, Rounds A, Heidari KS, Trasolini NA, Prodromo JP, Hatch GF, Weber AE. Risk Factors for Early Subsequent (Revision or Contralateral) ACL Reconstruction: A Retrospective Database Study. Orthop J Sports Med 2020;8(2):2325967119901173. Crossref

71. Rahardja R, Zhu M, Love H, Clatworthy MG, Monk AP, Young SW. Factors associated with revision following anterior cruciate ligament reconstruction: A systematic review of registry data. Knee 2020. [Article in press] Crossref
72. Grassi A, Macchiarola L, Lucidi GA, Stefanelli F, Neri M, Silvestri A, Della Villa F, Zaffagnini S. More Than a 2-Fold Risk of Contralateral Anterior Cruciate Ligament Injuries Compared with Ipsilateral Graft Failure 10 Years After Primary Reconstruction. Am J Sports Med 2020;48(2):310-7. Crossref

73. Hewett TE, Ford KR, Hoogenboom BJ, Myer GD. Understanding and preventing $A C L$ injuries: current biomechanical and epidemiologic considerations - update 2010. N Am J Sports Phys Ther 2010;5(4):234-51. https:// www.ncbi.nlm.nih.gov/pmc/articles/PMC3096145/

74. Myklebust G, Engebretsen L, Braekken IH, Skjølberg A, Olsen $\mathrm{OE}$, Bahr R. Prevention of anterior cruciate ligament injuries in female team handball players: a prospective intervention study over three seasons. Clin J Sport Med 2003;13(2):71-8. Crossref

75. Huo Z, Griffin J, Babiuch R, Gray A, Willis B, Marjorie S, Sun $\mathrm{S}$. Examining the feasibility of a Microsoft Kinect ${ }^{\mathrm{TM}}$ based game intervention for individuals with anterior cruciate ligament injury risk. Conf Proc IEEE Eng Med Biol Soc 2015;2015:7059-62. Crossref

76. Gray AD, Marks JM, Stone EE, Butler MC, Skubic M, Sherman SL. Validation of the Microsoft Kinect as a portable and inexpensive screening tool for identifying $A C L$ injury risk. Orthop J Sports Med 2014;2(2 Suppl). Crossref

77. Sherman SL, Gulbrandsen TR, Miller SM, Guess T, Willis BW, Blecha KM, Blecha KM, Huo Z, Skubic M, Gray AD. Mass screening of youth athletes for high risk landing patterns using a portable and inexpensive motion sensor device. Orthop J Sports Med 2016;4(7 Suppl 4). Crossref 